\title{
Participation in everyday activities and quality of life in pre-teenage children living with cerebral palsy in South West Ireland Vicki Mc Manus*1, Paul Corcoran ${ }^{2,3}$ and Ivan J Perry 4
}

Address: ${ }^{1}$ School of Nursing and Midwifery, UCC, Cork, Republic of Ireland, ${ }^{2}$ School of Public Health, UCC, Cork, Republic of Ireland, ${ }^{3}$ National Suicide Research Foundation, Cork, Republic of Ireland and ${ }^{4}$ School of Public Health, UCC, Cork, Republic of Ireland

Email: Vicki Mc Manus* - v.mcmanus@ucc.ie; Paul Corcoran - paul.nsrf@iol.ie; Ivan J Perry - I.Perry@ucc.ie

* Corresponding author

Published: 31 October 2008

BMC Pediatrics 2008, 8:50 doi:10.|| $86 /|47|-243 \mid-8-50$
Received: 22 April 2008

Accepted: 31 October 2008

This article is available from: http://www.biomedcentral.com/I47I-243I/8/50

(c) 2008 Mc Manus et al; licensee BioMed Central Ltd.

This is an Open Access article distributed under the terms of the Creative Commons Attribution License (http://creativecommons.org/licenses/by/2.0), which permits unrestricted use, distribution, and reproduction in any medium, provided the original work is properly cited.

\begin{abstract}
Background: Cerebral palsy (CP) is the most common cause of physical disability in children but its impact on quality of life is not well understood. This study examined participation in everyday activities among children without $\mathrm{CP}$ and children with mild, moderate and severe impairment due to CP. We then examined ten domains of quality of life in children with CP and investigated whether participation in everyday activities was associated with improved quality of life independent of gender, age and level of impairment.
\end{abstract}

Methods: This was a cross-sectional study of children aged 8-12 years based on two questionnaires, frequency of participation (FPQ) and KIDSCREEN, completed by parents of 98 children on the South of Ireland Cerebral Palsy Register (response rate $=82 \%$ ) and parents of 448 children attending two Cork city schools (response rate $=69 \%$ ) who completed one questionnaire (FPQ). Multiple linear regression was used: firstly to estimate the effect of severity of CP on participation in everyday activities independent of age and gender and secondly we estimated the effect of participation on quality of life independent of age gender and level of impairment.

Results: Participation in II of the 14 everyday activities examined varied across the children without $\mathrm{CP}$ and the children with varying severity of CP. In general, increased impairment decreased participation. Independent of age and gender, there was a highly significant decrease in overall participation with a fall of $-6.0(95 \% \mathrm{Cl}=-6.9$ to -5.2$)$ with each increasing level of impairment. The children with CP generally had high quality of life. Increased impairment was associated with diminished quality of life in just two domains - Physical well-being and Social support and peers. Overall participation in everyday activities was significantly associated with quality of life in 3 of the 10 domains (Physical well-being, Social support and peers \& Moods and emotions) in analysis adjusted for gender age and level of impairment.

Conclusion: While increased impairment due to CP restricts participation in the majority of everyday activities, the level of participation has a limited effect on the quality of life of the children with CP in age 8- 12 years. 


\section{Background}

Cerebral palsy (CP) is a chronic condition occurring in 2 to 3 per 1000 live births across Europe [1]. Defined as ' $a$ permanent disorder of the development of movement and posture, causing activity limitations that are attributed to non-progressive disturbances that occurred in the developing fetal or infant brain. The motor disorders of cerebral palsy are often accompanied by disturbances of sensation, perception, cognition, communication, and behaviour, by epilepsy and by musculoskeletal problems' [2]. Children with CP are representative of many disabled children as they have a range of physical, intellectual, hearing, vision and communication impairments, with a wide range of severity. The severity of the motor impairment, and the associated cognitive communicative and behavioural impairments, are different for each child with CP [3]. Because the level of severity differs, their level of participation in everyday activities will vary greatly among children living with $\mathrm{CP}$ [4]. Even though the incidence of CP has not changed in the past 20 years its impact on quality of life of diagnosed children is not well understood.

The centre was one of a number of other centres who took part in the large study Sparcle [5]. Analysis on the participation of the total Sparcle population found frequency of participation varied between countries; children with $\mathrm{CP}$ participated less frequently in some areas, but not all, compared to the general population [6]. This paper outlines the results from 2 instruments from that study: The Frequency of participation questionnaire (FPQ) measuring participation in everyday activities and the KIDSCREEN questionnaire measuring quality of life in children. Children with CP have a relatively stable impairment where participation and quality of life are influenced by social, educational and environmental factors, as well as by medical interventions. The age group 8-12 years was targeted because it was much less studied than other age groups of children.

Measuring participation and its frequency is important as it adds an important dimension to whether or not a child accomplishes participation. The FPQ was designed to examine participation i.e. the actual accomplishment of the participation in a meaningful way. The instrument allows comparison with the general population and allows examination of participation independent of assistance. Domains in the International classification of functioning, disability and health (ICF) [7] for activity and participation are one in the same. The ICF introduced the concept of participation, defining it as involvement in life situations [7-9] leading to a greater sense of identification and belonging [10]. In the area of disability attention has recently focussed on the real life issues for a child living with a disability - 'disabled children have the same aspirations as all children; security, respect, opportunities to learn new skills, meaningful occupation and the possibility of contributing to the lives of others' [11]. Clinicians therefore have to work towards real-life goals which include giving young children choices, and developing them as individuals. One way they can do this on a par is with adapted environments. One factor that influences participation is the barriers in the built environment. Adapted environments are essential for equal participation across all abilities. People with disabilities face barriers to physical activity in the social and built environments. To overcome these barriers people with disabilities need additional expenditure of resources to do so. Such were the findings of Kirchner et al [12] where problems with sidewalk pavement and poor drainage were the most cited environmental barriers. Participation is a valuable outcome measure for evaluating children's progress and for health services planning. Taking part in everyday activities for children with disabilities, on a par with children without disability, is vital for a sense of belonging within the community and an adapted environment facilitates this.

We know that children with physical and neurological disabilities enjoy the same activities as those without disabilities [13]. Children who are actively involved in school life can take advantage of educational and social benefits that arise from such an involvement. Children with CP are at increased risk of limitations to participation in every day activities $[14,15]$. Voorman et al [3] showed that activities and participation can be explained by the gross motor function level of a child, aged 9-16 years. Participation in everyday activities for children with disabilities is a goal shared by parents, service providers and organizations involved in children's rehabilitation [14].

Quality of life is used to describe a patient's condition at a level other than diagnosis $[16,17]$. The term quality of life has been defined as a 'subject-centred or individually appraised perspective on health [18].' Work with children with CP is only now coming to the forefront [18]. Quality of life is usually described as an overall assessment of wellbeing across various domains [19]. Examples of domains that are covered when exploring quality of life are physical well-being, social well-being, emotional well-being, school, access to services, and acceptance by others [19]. Bjornson and Mc Laughlin [20] found fewer than 5\% of the 1365 published measures of Quality of Life were applicable to children. The KIDSCREEN instrument has changed this by using the psychometrically valid and rigorously tested instrument on children $[21,22]$. Quality of life has been captured by this new European questionnaire - KIDSCREEN developed by taking account of the views of children and emphasising perception of psychosocial aspects of well-being rather than functioning or symptoms $[21,6]$. 
The aim of the study was to examine the frequency of activities by children in mainstream schools with and without CP. We also studied quality of life in children with $\mathrm{CP}$, as reported by their parents or foster parents, and the relation between participation in everyday activities and their quality of life. In particular the relationship between participation in everyday activities and quality of life has not been addressed in previous studies. Specific research questions were - Does severity of impairment associated with CP impact on participation in everyday activities? Among children with $\mathrm{CP}$, does participation in everyday activities affect quality of life after adjusting for severity of impairment?

\section{Methods}

This was a cross-sectional study of children with and without CP based on questionnaires completed by parents/ foster parents. Ethical approval was received from the National Research and Ethics Committee of the service provider. All parents gave written informed consent for the study subjects at the time of first contact.

\section{Participants}

\section{Children living with $C P$}

The South of Ireland Cerebral Palsy Register (SICPR) is a register of all child residents of the counties of Cork and Kerry who, at the age of four years or older, were diagnosed as living with CP. During the study period (20042005), the families of all 120 children on the SICPR aged 8-12 years were contacted, first by telephone and then by letter. Ninety-eight parents participated (response rate $=$ $82 \%$ ) and completed structured questionnaires that measured participation, quality of life and impairment and a range of other factors, in the presence of the study researcher, usually in their home and taking a duration of 90-120 minutes.

\section{Children not living with $C P$}

Via the school principals, the Frequency of Participation Questionnaire (FPQ) was sent to the parents of all 650 children aged 8-12 years attending two Cork schools. A total of 448 completed questionnaires were received by the researcher (response rate $=69 \%$ ). None of the children had a physical disability.

\section{Measures}

\section{Participation in everyday activities}

The ICF recognises potential overlap in the concepts of activity with participation and hence classifies it across the same domain. The Sparcle group considered the concepts to be separate and wanted to examine participation separately independent of adaptations or assistance required by a child in doing the activity.
Frequency of participation (FPQ) in 14 everyday activities was measured using the FPQ instrument, an instrument developed by Sparcle from the Life Habits questionnaire $[23,24]$. The Life-H instrument was used as the conceptual framework for the frequency items. It was designed for disabled children and has been used in children with CP [25]. Our instrument differs from the Life-H because it captures how frequently activities are done. The Sparcle group chose the items from the Life-H instrument so that they would be relevant to the general population also. The FPQ has face validity as the questions were derived from the content of the Life-H instrument. We did not undertake intra and inter observer reliability. The 14 FPQ activities are: eating out, leisure, computer use, helping with housework, riding a bicycle, tricycle or wheelchair, running errands, joining organized activities outside school (community), school activities, playing sports, playing non-sports, watching sports, doing arts and crafts, going to cinema (culture), and taking part in tourist activities. Frequency of participation in each activity was assessed using a six-point Likert scale (scored 0-5): never, less than once a month, about once a month, once every two weeks, about once a week a few times a week. Because of limited numbers at some levels of participation, each of the 14 items was collapsed to two levels for the data analysis relating to the 14 activities. The sum of the original 14 items (scored 0-5) was used to give an overall measure of participation in everyday activities (possible range 0-70). For respondents who failed to answer one, two or three items, the average of the answered items was imputed for the unanswered items. Cronbach's alpha was 0.63 for the overall measure of participation which indicates a moderate level of reliability [26,27]. Overall participation scores followed a Normal distribution.

\section{Quality of life}

Quality of life was measured using KIDSCREEN, a 52item generic health-related quality of life measure applicable to healthy and chronically ill children and adolescents aged 8-18 years and designed for child or parent report [21]. The KIDSCREEN instrument was used because it assesses across both healthy and ill children. It has been well validated psychometrically with 22,110 European children from the general population [21]. KIDSCREEN assesses ten domains of quality of life: physical wellbeing, psychological well-being, moods and emotions, self-perception, autonomy, parental relations, financial resources, social support and peers, school environment and social acceptance (bullying). The 52 items have a fivepoint Likert scale with two sets of possible responses: never, seldom, quite often, very often, always and not at all, slightly, moderately, very, extremely. For each domain, the relevant items are summed and scaled to yield a score in the range $0-100$ with higher scores indicating better quality of life. Cronbach's alpha was greater 
than 0.7 for all ten quality of life domains except one at 0.69 . These results suggest a high level of reliability for the domains [26,27]. Domain scores did not follow a Normal distribution because of the ceiling effect whereby high proportions of the children scored close to 100.

\section{Level of impairment of children living with CP}

Parents provided information about their child's gross motor function [28] and fine motor function [29]. CP type was available from the SICPR. Seizure activity, vision level, hearing level, feeding, communication and intelligence quotient (IQ) were recorded. Gross motor function and two-hand fine motor function were recorded according to the Gross Motor Function Classification System (GMFCS) and the Bimanual Fine Motor Function (BFMF) level. For the latter, levels I and II and levels III and IV were collapsed.

An overall, three-category measure of impairment was derived from the core impairment variables of gross motor function and IQ. Mild impairment was defined as GMFCS level I-III and IQ > 70. Moderate impairment was indicated by GMFCS level IV-V or IQ $<=70$. Severe impairment was defined as GMFCS level IV-V and IQ <= 70.

\section{Statistical analysis}

Data were analysed using SPSS v14. For the total study sample (i.e. children with CP and non-CP children), chisquare tests were used to assess the association between level of impairment and level of participation in each of the 14 everyday activities. Because overall participation scores followed a Normal distribution, the parametric ttest and one-way analysis of variance (ANOVA) were used to assess between-group differences with respect to two groups and more than two groups, respectively. Following statistically significant one-way ANOVA tests, Tukey's post hoc tests were used to identify the differing pairs of groups. A multiple linear regression model was estimated with overall participation in everyday activities as the dependent variable and gender, age and level of impairment as the independent variables. Diagnostic tests were used to check for violations of the assumptions inherent in linear regression models.

For the sample of children with CP, Mann-Whitney and Kruskall-Wallis tests were used to examine between-group differences in relation to the ten quality of life domains between two groups and more than two groups, respectively. For each quality of life domain, a multivariate linear regression model was estimated with quality of life as the dependant variable and gender, age, level of impairment and overall participation as the independent variables. Diagnostic tests were used to check for violations of the assumptions inherent in linear regression models.

\section{Results}

The gender balance in the samples of children with and without CP were similar, slightly more boys than girls. The age distributions showed some variation (Chi-square $=9.717, \mathrm{df}=3, \mathrm{p}=0.021$ ) with children aged $8-9$ years making up $41 \%$ of the CP sample and $29 \%$ of the Non-CP sample. Half were diagnosed spastic unilateral, 37.8\% (37) bilateral, with $6.1 \%$ (6) in both dyskinetic and ataxic CP (Table 1).

\section{Participation in everyday activities}

Level of impairment was significantly associated with participation in 11 of the 14 everyday activities examined (Table 2). No evidence of association was found in relation to eating out, riding a bicycle/tricycle/wheelchair and engaging in school activities. Using a computer was more common among the children with CP irrespective of their level of impairment. However, in general, increasing impairment was associated with decreasing participation.

Scores on the measure of overall participation in everyday activities ranged from 7 to 65 with a mean of 46.7 and standard deviation of 8.6. On average, girls had a marginally higher score than boys (mean: $47.3 \mathrm{v} 46.2$ ) but this difference was not statistically significant $(\mathrm{t}=-1.5, \mathrm{df}=$ $541, \mathrm{p}=0.11)$. One-way ANOVA indicated that overall participation did not differ by age $(\mathrm{F}=0.724, \mathrm{df}=3,539$, $\mathrm{p}=0.538$ ) but varied significantly by level of impairment $(\mathrm{F}=68.445, \mathrm{df}=3,539, \mathrm{p}<0.001)$. The post hoc tests indicated that the children at each of the four levels of impairment had significantly different levels of participation in everyday activities. Severely impaired children had the lowest level of participation (mean = 30.3), followed by those with moderate disability (mean $=35.4$ ), those with mild impairment (mean $=43.9)$ and finally the nonCP children $($ mean $=48.5)$.

The multiple linear regression model with overall participation as the dependant variable and age, gender and impairment as the independent variables was statistically significant $(\mathrm{F}=69.311, \mathrm{df}=3,539, \mathrm{p}<0.001)$. More than a quarter of the variation in overall participation was explained by the model (Adjusted $\mathrm{R}^{2}=27.4 \%$ ). The model indicated that overall participation was 1.2 higher in girls than in boys, a gender effect that just reached statistical significance ( $95 \% \mathrm{CI}=0.0$ to $2.5 ; \mathrm{t}=1.970$, $\mathrm{p}<0.05$ ). Participation was unrelated to age $(\mathrm{t}=0.640, \mathrm{p}=0.523)$. Independent of age and gender, there was highly significant evidence of a graded effect of impairment on participation $(\mathrm{t}=14.277 \mathrm{p}<0.001)$. From one level of impairment to the next (i.e. from non-CP to mild to moderate to severe $\mathrm{CP})$, there was a 6.0 decrease $(95 \% \mathrm{CI}=-$ 6.9 to -5.2 ) in a child's overall level of participation in everyday activities (Table 3 ). 
Table I: Characteristics of the non-cerebral palsy (Non-CP) and cerebral palsy (CP) children

\begin{tabular}{|c|c|c|}
\hline Characteristics & $\begin{array}{l}\text { Non-CP } \\
\text { N (\%) }\end{array}$ & $\begin{array}{l}\text { CP } \\
\mathbf{N}(\%)\end{array}$ \\
\hline \multicolumn{3}{|l|}{ Gender } \\
\hline Male & $208(46.4 \%)$ & $53(54.1 \%)$ \\
\hline Female & $240(53.6 \%)$ & $52(53.1 \%)$ \\
\hline \multicolumn{3}{|l|}{ Age } \\
\hline $8-9$ years & $128(28.6 \%)$ & $40(40.8 \%)$ \\
\hline 10 years & $109(24.3 \%)$ & $20(20.4 \%)$ \\
\hline II years & $123(27.5 \%)$ & $15(15.3 \%)$ \\
\hline 12 years + & $88(19.6 \%)$ & $23(23.5 \%)$ \\
\hline \multicolumn{3}{|l|}{ Classification (Gross Motor Function) levels I-V } \\
\hline 1 & & $37(37.8 \%)$ \\
\hline ॥ & & $22(22.4 \%)$ \\
\hline III & & $11(11.2 \%)$ \\
\hline IV & & $12(12.2 \%)$ \\
\hline V & & $16(16.3 \%)$ \\
\hline \multicolumn{3}{|l|}{ CP Type } \\
\hline Spastic unilateral & & $49(50.0 \%)$ \\
\hline Spastic bilateral & & $37(37.8 \%)$ \\
\hline Dyskinetic & & $6(6.1 \%)$ \\
\hline Ataxic & & $6(6.1 \%)$ \\
\hline \multicolumn{3}{|l|}{ Bimanual Fine Motor Function } \\
\hline Without Limitation & & $45(45.9 \%)$ \\
\hline Both Hands limited in fine skills or child needs help with tasks & & $33(33.7 \%)$ \\
\hline Child needs help and adapted equipment or total human assistance & & $20(20.4 \%)$ \\
\hline \multicolumn{3}{|l|}{ Seizures } \\
\hline No Seizures (either with or without medication) & & $82(83.6 \%)$ \\
\hline Seizures & & $16(16.4 \%)$ \\
\hline \multicolumn{3}{|l|}{ Feeding } \\
\hline No problems & & $73(74.5 \%)$ \\
\hline Feeds orally with difficulty, or by tube & & $25(25.5 \%)$ \\
\hline \multicolumn{3}{|l|}{ Communication } \\
\hline Normal & & $66(67.3 \%)$ \\
\hline Difficulty but uses less speech & & $8(8.2 \%)$ \\
\hline Uses non-speech for formal communication & & $13(13.3 \%)$ \\
\hline No formal communication & & $\mathrm{II}(\mathrm{II} .2 \%)$ \\
\hline \multicolumn{3}{|l|}{ Intellectual impairment } \\
\hline None or mild (IQ >70) & & $54(55.1 \%)$ \\
\hline Moderate or severe $(\mathrm{IQ}<=70)$ & & $43(43.9 \%)$ \\
\hline Missing & & $\mathrm{I}(\mathrm{I} \%)$ \\
\hline \multicolumn{3}{|l|}{ Hearing } \\
\hline Does not need hearing aid & & $96(98 \%)$ \\
\hline Needs hearing aids due to profound or severe loss $>70$ decibels & & $2(2 \%)$ \\
\hline \multicolumn{3}{|l|}{ Vision } \\
\hline Has useful vision & & $96(91.8 \%)$ \\
\hline Blind or no useful vision & & $8(8.2 \%)$ \\
\hline
\end{tabular}

\section{Quality of life in children with CP}

The distribution of scores on the ten domains of quality of life is illustrated in Figure 1. Ceiling effects, in that a high proportion of the children scored at or close to the maximum value, were evident in relation to Social acceptance and bullying, Financial resources, Self perception, Parent relation and home life, Social environment and Mood and emotions.
Increased severity of impairment was associated with significantly diminished quality of life but only in relation to two domains - Physical well-being $(p<0.05)$ and Social support and peers $(\mathrm{p}<0.01)$. Respectively, children with mild, moderate and severe impairment had median scores of 65.0, 57.5 and 45.0 for Physical well-being and 62.5, 50.0 and 40.0 for Social support and peers. 
Table 2: The association between participation in everyday activities and level of impairment

\begin{tabular}{|c|c|c|c|c|c|c|}
\hline & & Non-CP & Mild disability & Moderate disability & Severe disability & p-value* \\
\hline \multirow[t]{2}{*}{ Eat out } & No more than once per month & $242(54.0 \%)$ & $26(50.0 \%)$ & $10(43.5 \%)$ & $16(69.6 \%)$ & 0.308 \\
\hline & More than once a month & $206(46.0 \%)$ & $26(50.0 \%)$ & $13(56.5 \%)$ & 7 (30.4\%) & \\
\hline \multirow[t]{2}{*}{ Leisure } & $<$ few times per week & $10(2.2 \%)$ & $3(5.8 \%)$ & $3(13.0 \%)$ & $4(17.4 \%)$ & $<0.001$ \\
\hline & Few times per week & $438(97.8 \%)$ & 49 (94.2\%) & $20(87.0 \%)$ & $19(82.6 \%)$ & \\
\hline \multirow[t]{2}{*}{ Computer } & $<$ few times per week & $254(57.2 \%)$ & $18(34.6 \%)$ & $6(26.1 \%)$ & $9(39.1 \%)$ & $<0.001$ \\
\hline & Few times per week & $190(42.8 \%)$ & $34(65.4 \%)$ & $17(73.9 \%)$ & $14(60.9 \%)$ & \\
\hline \multirow[t]{2}{*}{ Housework } & $<$ few times per week & $217(48.7 \%)$ & $25(48.1 \%)$ & $18(78.3 \%)$ & $19(82.6 \%)$ & $<0.001$ \\
\hline & Few times per week & $229(51.3 \%)$ & $27(51.9 \%)$ & $5(21.7 \%)$ & $4(17.4 \%)$ & \\
\hline \multirow[t]{2}{*}{ Riding a bike } & $<$ few times per week & $279(62.8 \%)$ & $28(53.8 \%)$ & $13(56.5 \%)$ & $9(39.1 \%)$ & 0.089 \\
\hline & Few times per week & $165(37.2 \%)$ & $24(46.2 \%)$ & $10(43.5 \%)$ & $14(60.9 \%)$ & \\
\hline \multirow[t]{2}{*}{ Run errands } & $<$ once per week & $192(43.5 \%)$ & $26(50.0 \%)$ & $16(69.6 \%)$ & $16(69.6 \%)$ & 0.009 \\
\hline & At least once per week & $249(56.5 \%)$ & $26(50.0 \%)$ & 7 (30.4\%) & 7 (30.4\%) & \\
\hline \multirow[t]{2}{*}{ Community } & $<$ few times per week & $225(51.3 \%)$ & $35(67.3 \%)$ & $21(95.5 \%)$ & $23(100 \%)$ & $<0.001$ \\
\hline & Few times per week & $214(48.7 \%)$ & $17(32.7 \%)$ & I (4.5\%) & $0(0 \%)$ & \\
\hline \multirow[t]{2}{*}{ School activities } & $<$ once per month & 275 (63.7\%) & 36 (73.5\%) & $15(68.2 \%)$ & 17 (77.3\%) & 0.330 \\
\hline & At least once per month & $157(39.3 \%)$ & $13(26.5 \%)$ & 7 (31.8\%) & 5 (22.7\%) & \\
\hline \multirow[t]{2}{*}{ Play sports } & $<$ few times per week & $91(20.7 \%)$ & $24(47.1 \%)$ & $18(81.8 \%)$ & $19(82.6 \%)$ & $<0.001$ \\
\hline & Few times per week & $349(79.3 \%)$ & $27(52.9 \%)$ & $4(18.2 \%)$ & $4(17.4 \%)$ & \\
\hline \multirow[t]{2}{*}{ Play non-sports } & $<$ few times per week & $193(43.8 \%)$ & $19(36.5 \%)$ & $12(54.5 \%)$ & $17(77.3 \%)$ & 0.008 \\
\hline & Few times per week & $248(56.2 \%)$ & $33(63.5 \%)$ & $10(45.5 \%)$ & 5 (22.7\%) & \\
\hline \multirow[t]{2}{*}{ Watch sports } & $<$ few times per week & $230(52.2 \%)$ & $38(74.5 \%)$ & 21 (9l.3\%) & 21 (9l.3\%) & $<0.001$ \\
\hline & Few times per week & $211(47.8 \%)$ & $13(25.5 \%)$ & $2(8.7 \%)$ & $2(8.7 \%)$ & \\
\hline \multirow[t]{2}{*}{ Do crafts } & $<$ few times per week & $233(52.6 \%)$ & $37(72.5 \%)$ & $19(82.6 \%)$ & 17 (73.9\%) & $<0.001$ \\
\hline & Few times per week & $210(47.4 \%)$ & $14(27.5 \%)$ & $4(17.4 \%)$ & $6(26.1 \%)$ & \\
\hline \multirow[t]{2}{*}{ Culture } & $<$ Once per month & $127(28.5 \%)$ & $18(35.3 \%)$ & $13(56.5 \%)$ & $18(78.3 \%)$ & $<0.001$ \\
\hline & At least once per month & $318(71.5 \%)$ & $33(64.7 \%)$ & $10(43.5 \%)$ & $5(21.7 \%)$ & \\
\hline \multirow[t]{2}{*}{ Tourist } & $<$ Once per week & $254(57.1 \%)$ & 39 (75.0\%) & $19(86.4 \%)$ & $15(68.2 \%)$ & 0.004 \\
\hline & At least once per week & 191 (42.9\%) & $13(25.0 \%)$ & $3(13.6 \%)$ & 7 (31.8\%) & \\
\hline
\end{tabular}

* p-values based on chi-square tests with three degrees of freedom

Independent of gender, age and level of impairment, overall participation in everyday activities had a significant effect on three quality of life domains. A one-unit increase in participation was associated with increases of 7.8, 4.5 and 13.9 in quality of life related to Physical well-being, Moods and emotions and Social support and peers, respectively.

\section{Discussion}

\section{Key findings}

There was a stepped decrease in participation and quality of life from that of children without $\mathrm{CP}$ to those with mild, moderate and severe CP. Of the 14 everyday activities examined in the study, nine were affected by how impaired the child with CP was. The more impaired the child was the more affected they were in everyday activi-

Table 3: Results of multiple linear regressions of quality of life domains on overall participation in everyday activities, gender, age and level of impairment

\begin{tabular}{|c|c|c|c|c|c|c|c|c|}
\hline Quality of life domain & $\mathbf{F}$ & df & p-value & $\mathbf{R}^{2}(\%)$ & $\mathbf{B}^{*}$ & $95 \% \mathrm{Cl}^{*}$ & $\mathbf{t}^{*}$ & p-value* \\
\hline Physical well-being & 3.69 & 4,85 & 0.008 & 14.8 & 7.8 & $1.3-14.3$ & 2.4 & 0.019 \\
\hline Psychological well-being & $1.5 \mathrm{I}$ & 4,89 & 0.206 & 6.4 & 4.4 & $-0.5-9.4$ & 2.5 & 0.079 \\
\hline Moods \& emotions & 1.59 & 4,86 & 0.183 & 6.9 & 4.5 & $0.4-8.6$ & 2.2 & 0.031 \\
\hline Self perception & 0.45 & 4,84 & 0.769 & 2.1 & 0.8 & $-4.1-5.7$ & .33 & 0.741 \\
\hline Autonomy & 0.86 & 4,84 & 0.492 & 3.9 & -0.2 & $-6.4-6.0$ & -.06 & 0.952 \\
\hline Parent relation \& home life & 0.94 & 4,88 & 0.446 & 4.1 & 3.7 & $-1.5-9.0$ & 1.4 & 0.158 \\
\hline Financial resources & 0.61 & 4,59 & 0.656 & 4.0 & 5.3 & $-6.2-16.7$ & $.13 \mid$ & 0.361 \\
\hline Social support \& peers & 8.51 & 4,84 & $<0.001$ & 28.9 & 13.9 & $7.7-20.0$ & 4.4 & $<0.001$ \\
\hline School environment & 2.73 & 4,86 & 0.034 & 11.3 & 3.7 & $-1.1-8.6$ & 1.5 & 0.129 \\
\hline Social acceptance \& bullying & 0.81 & 4,87 & 0.524 & 3.6 & -0.3 & $-5.1-4.5$ & -.12 & 0.903 \\
\hline
\end{tabular}

* Unstandardised coefficient and association statistics for overall participation after adjustment for gender, age and level of impairment 


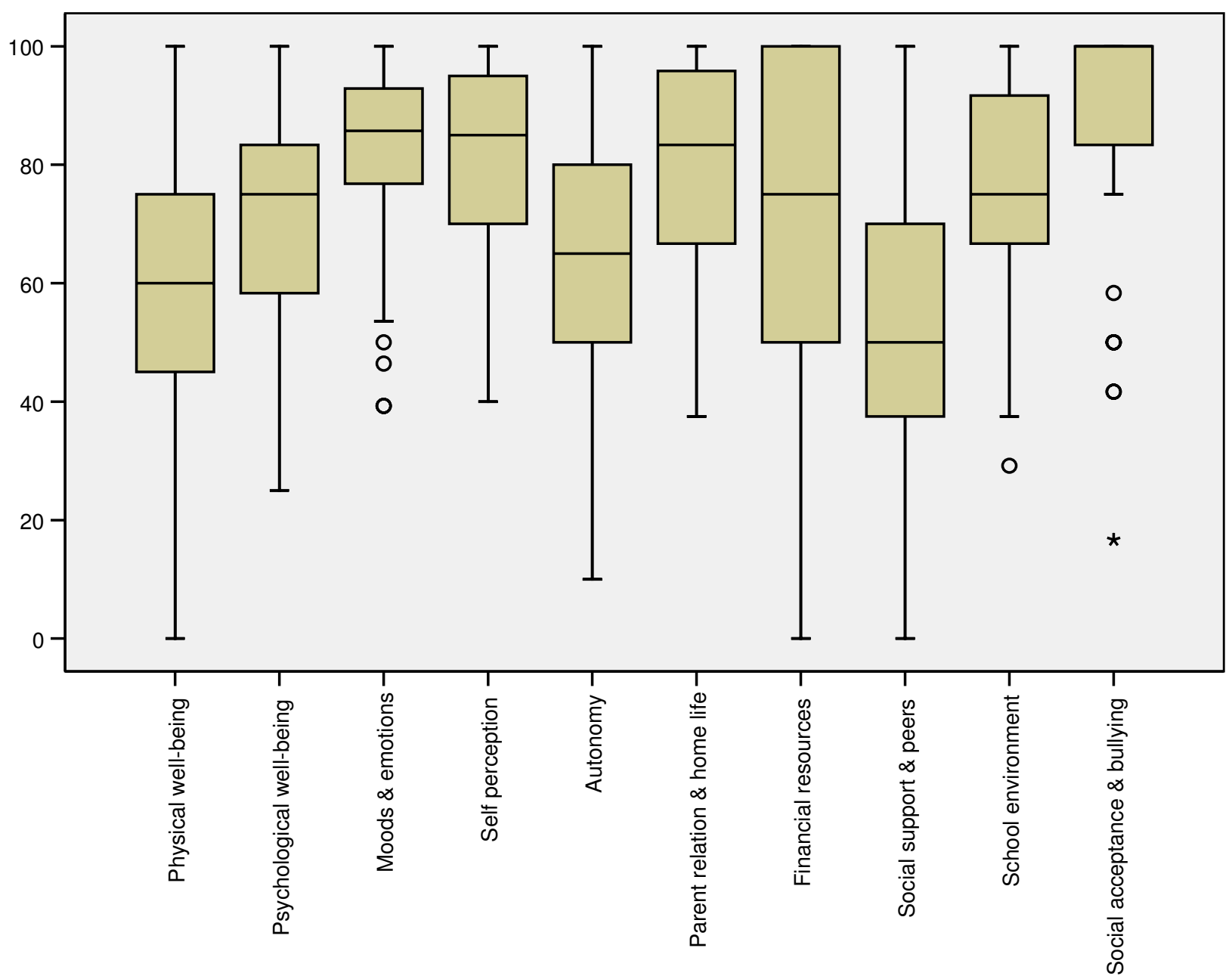

Figure I

Box-plots of the 10 quality of life domains in 98 children with CP aged 8- I 2 years.

ties. Girls had a slightly higher level of participation than boys in both samples, CP and Non-CP. There was a graded change in the level of impairment with the mean 43.89 for the mildly affected and 30.32 for those severely affected. In essence the mildly affected group was significantly more active than groups moderately impaired or the severely impaired group, the moderately impaired group was not significantly different than the severely impaired group. In other words the magnitude of the difference between the groups is quite small; approximately $10 \%$ difference between the mean score of those mildly affected and those living without a disability.

\section{Limitations}

It is a weakness of the study that we did not include social class or income as a covariate in relation to the CP children. Income has been examined previously [14] and should be routinely included in Registry-based studies as income information is generally available on registers worldwide. When the non-CP children were examined they were found to be of average social class level and there was no evidence of either deprivation or high social class on visitations.

The sample was taken from a defined geographical area where the same services were available to the families of the CP children. Carrying out such a study on a national 
basis would have resulted in a more representative sample in the context of varied services.

The focus on measuring frequency of participation alone in the non CP children is a limitation of the study. In hind sight quality of life could have been measured and explored in both samples to enable a direct comparison across both populations of $\mathrm{CP}$ and non $\mathrm{CP}$ children in the age group.

The KIDSCREEN domains were not normally distributed which raises the question of suitability of using linear regression. Diagnostic tests were carried out following the linear regression analyses, the results of which showed no violation of the assumptions related to the model.

Despite these limitations the results contribute towards an understanding of the levels of participation and quality of life of children living with $\mathrm{CP}$ in Ireland.

This study makes an important and novel contribution to the literature and has critical implications for policy and practice in Ireland. It adds a further important dimension to whether Irish children participate and to what extent.

Beckung [28], Shenker [8] and Voorman [3] all found that impaired motor abilities explained a significant amount of the level of participation among children living with $\mathrm{CP}$; our evidence showed the same; that as one moves from one level of impairment to another the average participation score is reduced by -6.97. In essence moving from one level of disability to the next a score of -6.97 comes off ones FPQ score. One area that can help with a child's level of impairment is adaptations in the environment. If the local health service provider provided for adaptations with the child's environment it would improve access and participation.

When we look at the two populations (CP and Non-CP) participation rates do not compare; the mean participation score moves gradually from 45-46-47 improving with age in the Non-CP population but in the CP population this is not the case, rather it moves 38-41-35-38. Anecdotally it is surprising to find that it was only 3 domains that were significant. And yet if we compare the Irish children with CP to the Swedish and Italian children with $\mathrm{CP}$, Irish children participated less in most domains [6]. It was only in the Danish dataset that both CP and non CP children were on a par. Denmark is considered the front runner for valuing inclusion in disabled children [30]. All areas in Denmark have equal access [31]. One of the structures in place to facilitate this is public transport. Ireland must prioritise access for all.
The analysis of the full Sparcle dataset [6] found that in nearly all areas children with CP participated less than those not affected. But when in school all levels of impairment participated as much or more when activities were organised by the school [6]. This shows again that when the adaptations and systems are in place the impact of the impairment is lessened.

The research achieved what it set out to achieve, specifically to explore the severity of impairment of children diagnosed with CP, how it impacts on their quality of life, how the severity of their impairment impacts on their frequency of participation in activities and lastly to examine if participation in activities differed between children with $\mathrm{CP}$ and children in mainstream schools. It can be seen from the work that only in the severely affected children is both participation and quality of life affected. Therefore the hypothesis has to be accepted in that impairment does impact on quality of life and participation levels and that participation does differ between children living with $\mathrm{CP}$ and those age matched children without $\mathrm{CP}$, if only marginally.

\section{Quality of life}

The parents reported that the children with $\mathrm{CP}$ generally had a high quality of life. Increased impairment was associated with diminished quality of life in just two domains; Physical well-being and Social support and peers. However, independent of gender, age and level of impairment, overall participation in everyday activities significantly increased quality of life in these two domains and in the domain Moods and emotions. The low Physical wellbeing and Social support and peers domains means that the parents of these children think the children are lonely and find it difficult to make friends and communicate with their peers. This difficulty could be attributable to the environmental adaptations necessary to make friends such as accessing cinemas and restaurants to hang out with friends. This research will not change attitudes towards young people but could facilitate access to an improved social life by raising the awareness that they are lonely and do have physical impairments that stop them from getting places. Adaptations could improve their quality of life even further.

Although several studies have reported quality of life results for children with $\mathrm{CP}[20,30]$ few studies have assessed parent reported quality of life across a comprehensive set of subject domains for a group of children that are representative in all levels of severity in CP affected children. Another implication of our findings is that we must not consider parent reports equivalent to child's' report. It simply reflects a different perspective [6]. In the Sparcle paper most of the children were too severely 
affected to self report emphasising the importance of some report on the situation being essential.

\section{Conclusion}

To our knowledge, this study is the first of its kind in Ireland looking at participation rates and quality of life in a population of children living with CP. It is the first positive news parents of Irish children with $\mathrm{CP}$ have received to date. When diagnosed it is now possible to tell parents of children with CP that in 9 activities children with CP participate well in everyday activities. Compared with the mainstream non affected population, children with mild CP compare well and do participate admirably with their peers. The findings concurred with similar work across all countries within the Sparcle project [6]. This is new knowledge for Irish parents and policy makers in the Health Care Service. It adds to the ongoing process of trying to better understand $\mathrm{CP}$ and its impact on the lives of those affected by it. The outcomes of this research recommend that parents, clinicians and educators of children with $\mathrm{CP}$ continue to encourage children with disabilities to take part in daily activities along side their mainstream peers in school and in their community. This can be done with support from local health services in funding adaptations. These results allow for informed service planning in the near future. The adaptations will encourage families to stay in the mainstream school system leading ultimately to a better quality of life for all concerned.

Further studies, based on longitudinal designs, should be carried out to determine the quality of life, participation levels and to identify the factors that predict the course of functioning in adolescents and adults with $\mathrm{CP}$ in the years ahead. These studies need to be done both nationally and internationally for the development of intervention programmes, policy and for planning the services that are needed for children, adolescents and adults and their families living with CP.

\section{Competing interests}

The authors declare that they have no competing interests.

\section{Authors' contributions}

VMM and PC hereby certify that they had access to all the data from the study and take responsibility for the integrity of the data and the accuracy of the analysis. IJP supervised the work. All authors (VMM, PC, IJP) contributed to the design of the study, interpretation of the data and read the manuscript critically. VMM is responsible for the writing. All authors' (VMM, PC and IJP) have read and approved the final script.

\section{Acknowledgements}

Based on work carried out at the Research Department Enable Ireland

Cork Services. We are grateful to the parents who took the time to fill out the questionnaires in their busy lives. The Sparcle study was funded by the
European Commission Research Framework 5 Programme - Grant number QLG5-CT-2002-00636. We acknowledge the SPARCLE co-ordinating centre for the data entry specifically and their work developing and co-ordinating the Sparcle study in general.

\section{References}

I. Cans C: Surveillance of cerebral palsy in Europe: a collaboration of cerebral palsy surveys and registers. Dev Med Child Neurol 2000, 42:816-824.

2. Rosenbaum P, Paneth N, Leviton A, Goldstein M, Bax M, Damiano D, Dan $B$, Jacobsson $B$ : $A$ report: the definition and classification of cerebral palsy April 2006. Dev Med Child Neurol Suppl 2007, 109:8-|4.

3. Voorman JM, Dallmeijer AJ, Schuengel C, Knol DL, Lankhorst GJ, Becher JG: Activities and Participation of 9- to I3-year old children with cerebral palsy. Clinical Rehabilitation 2006, 20:937-948.

4. Cans C: Prevalence and characteristics of children with cerebral palsy in Europe. Dev Med Child Neurol 2002, 44:633-640.

5. Dickinson HO, Parkinson KN, Ravens-Sieberer U, Schirripa G, Thyen U, Arnaud C, Beckung E, Fauconnier J, McManus V, Michelsen SI, Parkes J, Colver A: Self-reported quality of life of 8- 12 year old children with cerebral palsy: a cross-sectional European study. Lancet 2007, 369(9580):2I7|-2I78.

6. Michelsen SI, Flachs EM, Uldall P, Eriksen EL, McManus V, Parkes J, Arnaud C, Parkinson K, Thyen U, Beckung E, Dickinson H, Fauconnier J, Marcelli M, Colver A: Frequency of participation of 8- 12 year old children with cerebral palsy; a multi-centre cross sectional European study. European Journal of Paediatric Neurology 2008 in press.

7. World Health Organisation: International classification of functioning, disability and health. World Health Organisation, Geneva; 200I

8. Schenker R, Coster WJ, Parush S: Participation and activity performance of students with cerebral palsy within the school environment. Disabil Rehabil 2005, 27(10):539-552.

9. Morris C, Kurinczuk JJ, Fitzpatrick R: Child or family assessed measures of activity performance and participation for children with cerebral palsy: a structured review. Child: Care, Health \& Dev 2005, 3 I (4):397-407.

10. Finn JD: Withdrawing from school. Review of Educational research 1989, 59:1 17-142.

II. McConachie H, Colver AF, Forsyth RJ, Jarvis SN, Parkinson K: Participation of disabled children: how it should be characterized and measured? Disability and Rehabilitation 2006, 28( I 8): I I 57- I I 64.

12. Kirchner CE, Gerber EG, Smith BC: Designed to deter. Community barriers to physical activity for people with visual or motor impairments. Am J Prev Med 2008, 34(4):349-52.

13. Heah T, Case T, McGuire B, Law M: Successful participation: the lived experience among children with disabilities. Can J Occup Ther 2007, 74(I):38-47.

14. Law M, King G, King S, Kertoy M, Hurley P, Rosenbaum P, Young N Hanna S: Patterns of participation in recreational and leisure activities among children with complex physical disabilities. Dev Med Child Neurol 2006, 48:337-342.

15. King G, Law M, King S, Hurley P, Hanna S, Kertoy M, Rosenbaum P, Young N: Children's Assessment of Participation and Enjoyment (CAPE) and Preferences for Activities of Children (PAC). San Antonio. Harcourt Assessment; 2004.

16. Colver AF, Sethumadhavan T: The Term diplegia should be abandoned. Arch Dis Child 2003, 88(40):286-90.

17. Colver AF: 'A shared framework and language for childhood disability'. Dev Med Child Neurol 2005, 47(I I):780-784.

18. Bullinger $M$, Schmidt S, Peterson C: DISABKIDS group assessing quality of life of children with chronic health conditions and disabilities: a European approach. Int J Rehabil res 2002, 25(3): 197-206.

19. Waters E, Maher E, Salmon L, Reddihough D, Boyd R: Development of a condition specific measure of quality of life for children with cerebral palsy: empirical thematic data reported by the parents and children. Child Health Care and Dev 2005, 3 I: I 27-I 35.

20. Bjornson KF, Mc Laughlin J: The measurement of health related quality of life in children with cerebral palsy. Eur J Neurol 200I, 8(suppl 5): 183-193. 
21. Ravens-Sieberer U, Gosch A, Rajmil L, Erhart M, Bruil J, Duer W, Auquier P, Power M, Abel T, Czemy L, Mazur J, Czimbalmos A, Tountas Y, Hagquist C, Kilroe J, the European KIDSCREEN Group: KIDSCREEN-52 quality-of-life measure for children and adolescents. Expert Review of Pharmacoeconomics \& Outcomes Research 2005, 5(3):353-364.

22. Detmar SB, Bruil J, Ravens-Sieberer U, Gosch A, Bisegger C: The Use of Focus Groups in the Development of the KIDSCREEN HROL Questionnaire. Qual Life Res 2006.

23. Fougeyrollas $P$, Noreau L, Bergeron $H$, Cloutier R, Dion SA, St-Michel $G$ : 'Social consequences of long term impairments and disabilities: conceptual approach and assessment of handicap'. International Journal of Rehabilitation Research 1998, 21: | 27- |4 I.

24. Lepage C, Noreau L, Bernard PM, Fougeyrollas P: Profile of handicap situations in children with cerebral palsy. Scand J Rehabil Med 1998, 30:263-272.

25. Palisano RJ, Hanna SE, Rosenbaum PL, Russell DJ, Walter SD, Wood EP, Raina PS, Galuppi BE: Validation of a model of gross motor function for children with cerebral palsy. Phys Ther 2000, 80:974-985.

26. Cronbach 니: Coefficent alpha and the internal structure of tests. Psychometrika 1951, 16:297-334.

27. Pallant J: SPSS Survival manual - A step by step guide to data analysis using SPSS. Open University Press Buckingham; 2001.

28. Beckung E, Hagberg G: Neuroimpairments, activity limitations, and participation restrictions in children with cerebral palsy. Dev Med Child Neurol 2002, 44:309-316.

29. Palisano R, Rosenbaum PL, Walter SD, Russell DJ, Wood E, Galuppi BE: The Gross Motor Function Classification System for cerebral palsy. Dev Med Child Neurol 1997, 39:2 I4-23.

30. Tisdall K: National contexts affecting the lives of disabled children in Denmark, France, Germany, Ireland, Italy, Sweden and UK (England and Northern Ireland). Volume I. Newcastle: University of Newcastle upon Tyne; 2006.

31. Tisdall K: National contexts affecting the lives of disabled children in Denmark, France, Germany, Ireland, Italy, Sweden and UK (England and Northern Ireland). Volume 2. Newcastle: University of Newcastle upon Tyne; 2006.

\section{Pre-publication history}

The pre-publication history for this paper can be accessed here:

http://www.biomedcentral.com/1471-2431/8/50/prepub

Publish with Biomed Central and every scientist can read your work free of charge

"BioMed Central will be the most significant development for disseminating the results of biomedical research in our lifetime. "

Sir Paul Nurse, Cancer Research UK

Your research papers will be:

- available free of charge to the entire biomedical community

- peer reviewed and published immediately upon acceptance

- cited in PubMed and archived on PubMed Central

- yours - you keep the copyright 